\title{
Toward a semantic analysis for E-learning and E-assessment system of apprentices
}

\author{
Wiem Ben Khalifa ${ }^{1}$, Dalila Souilem ${ }^{2}$ and Mahmoud Neji ${ }^{3}$ \\ ${ }^{1}$ University of Dammam, Dammam, Saudi Arabia \\ ${ }^{2}$ University of Umm Qura, Mecca, Saudi Arabia \\ ${ }^{3}$ University of Sfax, Sfax, Tunisia
}

correspondence should be addressed to: Wiem Ben Khalifa; wiembenkhlifa@gmail.com

Received date: 24 April 2017; Accepted date: 12 June 2017; Published date: 16 November 2017

Academic Editor: Alaa Abdul Salam Alyamani

Copyright (c) 2016. Wiem Ben Khalifa, Dalila Souilem and Mahmoud Neji. Distributed under Creative Commons CC-BY 4.0

\begin{abstract}
E-Learning is operative, pertinent for tasks and learning just in time giving to the learning requests of the new and dynamic world. The term semantic web and the social Web development rise several questions concerning the personalization of a associate way of learning using intelligent filtering means of educational resources issued from digital networks. We propose personalized learning courses dealing with a first educational course defined upstream. Resuming the context and the personalization interests, we also propose to anchor learning customization in the community interest within a group of learners enrolled in the same training. This reflection is maintained through displaying active and semantic system of learning dedicated to the customized constitution in order to measure courses in the expected time.
\end{abstract}

Keywords: semantic, E-learning, ontology, E-assessment system, learning customization

\section{Introduction}

The contemporary sociotechnical context distinguishing Web evolution, qualified as social Web and semantic Web, aims to promote the customizing dimension of learning. This dimension has to be investigated due to its situation between three strongly evolving dimensions during the last years. Indeed, the online learning systems of LCMS type (Learning Content Management System) are influenced by the semantic Web technologies prevailing evolution. The digital educational resources, the fundamental learning systems elements, are the earlier to alter themselves to these technologies development in order to be converted into educational objects. In a

Cite this Article as: Wiem Ben Khalifa, Dalila Souilem and Mahmoud Neji (2017), " Toward a semantic analysis for E-learning and E-assessment system of apprentices ", Journal of Software \& Systems Development, Vol. 2017 (2017), Article ID 289051, DOI: 10.5171/2017.289051 
parallel way with the social Web expansion, they have built up contents creation practices, division, remixing, vote, information search via forums, blogs, instant discussions, wikis, social media, etc. These well anchored social Web practices, which are nowadays in Internet users' habits, lean more and more on the technologies of semantic Web. Moreover, they pave the way for training personalized careers as well as custom-made product in the expected time. The purpose of this article is questioning about how to support the personalized learning using social web recent practices and semantic Web evolutions. Namely, how to articulate the personalization needs for learning with social Web practices, by taking into consideration structuring the matters supported by semantic Web?

For that, we will introduce the active and semantic learning system. This system will admit suggesting educational complements detected on Web in a penetrating manner. This will provide the training personalized course structure. Based on semantic Web technologies, this system sets up a semantic organization of the matters published on social media, a marking of the latter and their position as well as their sharing objective. It consists of a semantic core in its focus and several ontologies related between them .It can also handle the ontologies connections and also settle suitable requests by well questioning the semantic databases linked to the different ontologies of the system like the external web resources of semantic blogs type or semantic wikis.

By investigating the different dimensions of the current context that allows envisaging a personalized learning, we have to stipulate the system favoring features and speculate the stakes in this personalization.

\section{Personalized learning}

The active and semantic system of learning, the subject of our work, has as a goal to satisfy the different demands of the personalized courses first of all; then to reduce the detected problems and finally to classify the appropriate subject matters in a personalized courses perspective by teaching and assimilating the mostly individually students ongoing applications, the comments, the remarks, the daily practices marking of Web. This first point will be granted to establishing the context and to citing the needs at stake.

\section{The criteria of personalization}

To suggest personalized ways of training, it is recommended to take into consideration several criteria describing the learners' profiles. The description of the learner within the system collects his learning objectives definition, his favored manner of learning, and also his proficiency. Through the traces of the learner the system can develop the learner's profile over time.

Then, with reference to semantic Web technologies, the system will pick out the educational means published on the digital networks that are not only limited to the Web but also including banks data and local databases.

However, this system is based upstream on the learning career that divides learning into several chronological phases, each phase has prerequisites to achieve a goal clarified by skills to be acquired.

The elements used in our study/research are: firstly the school learning framework, secondly the organization of the educational aims that allow acquiring various skills, the tools that allow checking the objectives and the acquired skills, and also the opening of digital networks system in order to integrate complementary pedagogical means.

The integration of the experiences, estimated by a set of open answered questions can give rise to two possibilities. Either the objectives are not attained or only partially attained. In this case, educational complements stemming from digital pedagogical resources will be suggested to enhance knowledge acquisition. When the objectives are widely reached; the planned educational 
complements will then focus on complementing and exceeding the initial objectives [9]. Hence, the educational objects designed in the learning course depend on the educational complements in the light of the training progress. These complements can be selected from different resources such as blogs postings, wiki articles, videos; exercises etc. they can also be selected from other educational materials. Such integration of these educational complements in the training courses is interesting because it simplifies revising personalized courses as well as offers to the learner extra educational resources based on his profile.

EO: Educational Objects ; SOAQs: Short and Open Answer Question

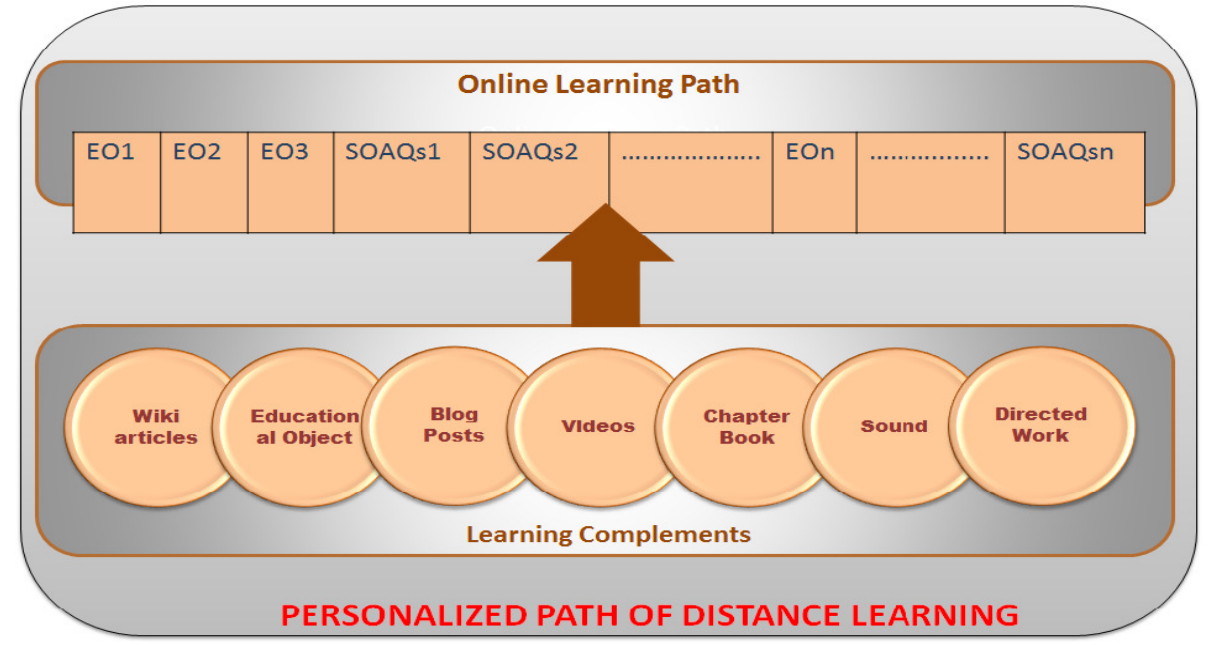

Fig. 1: Personalized Path of distance learning

\section{Sharing contents}

It is necessary for us to rely on sharing contents practices of learners, as Internet users within their daily practices framework of Web. This is due to the fact that they will play an important role to locate, annotate and comment on the educational objects which will elaborate the system. Among the big Web evolution tendencies which outline the evolution of these content sharing practices recently, we intend to highlight some innovations which influenced, in their turn, the conception of the learning system on which we work: The enhancement of the contents structuring, as well at the level of tools (particularly with semantic Web technologies and protocols evolutions(RDF, SPARQL , OWL etc.) than practices (in particular with the development of the indexation practices) ; The opening, the interweaving of systems, yesterday closed or separated tools (in particular the systems of learning: Learning Content Management System; The personalization of the contents presented to Internet users (at the level of the search engines results, suggestions of complementary contents in that consulted, of content sharing between Internet users etc.).

All of these evolutions together lead to the individual practices development of contents sharing and also to the expectation production in terms of personalized contents.

\section{Methodology}

The function of the system that we established is to pick the necessary digital educational materials (rather educational objects) to provide the learner's apprenticeship. From a data graph, this system proposes, in due course, further educational custom-made complements. 


\section{Learner's profile}

This system concentrates on the learners so that they set up personalized and heterogeneous courses, either because they have blanks to fill, or due to the fact that they learn more quickly than the others. The selection of the educational complementary materials takes into consideration the different methods of teaching and the objectives of its training. Actually, the system works by linking the specific information to the learner profile with Meta given associated with the educational materials published on digital networks.

A learner profile encloses four different parts. Each part describes respectively the educational career of the student, his experiences and his gaps of the moment, his/her preferences and the tracks which the learner left on the system. The ontology modeling the preferences of the described learner the peculiarities of the learner according to four points: first the perception of the learners: sensory vs. intuitive, then the favored format of the learner: visuals vs. Verbal picture, third the cooperation of the learner: active person vs. thoughtful and the contents display: sequential vs. global.

\section{A graph of data}

The figure below introduces the different modules of the system that have unique roles in accordance with the tasks to realize. For each module of the system, there is an ontology describing the corresponding resources stored in the data basis. The system involves six valuable ontologies to further describe the semantic information that will be put in report to select the educational complementary materials:

- The ontology Administration disgraces the administrative data of the high;

- The ontology to use Profiles describes the learning profile of a student. It involves the learner's ontology preferences;

- The ontology objects provide the required vocabulary to annotate the educational objects. This ontology joins the set of Meta given;

- The ontology of the skills allows determining the appropriate meadow and the experiences;

- The ontology of the questions allows creating questionnaires used to validate the skills acquisition or identify the learner's weak points;

- The ontology of evaluations allows the users to annotate either the internal or the external educational resources of the system.

The system can also utilize other current ontologies to recognize, for example, the notes corresponding to other contexts rather than learning. These modules interact between them through a semantic pit (Semantic Kernel). The latest maintains the connections among the ontologies and guarantees data exchanges between the module "use interface" and the other modules of the system. 


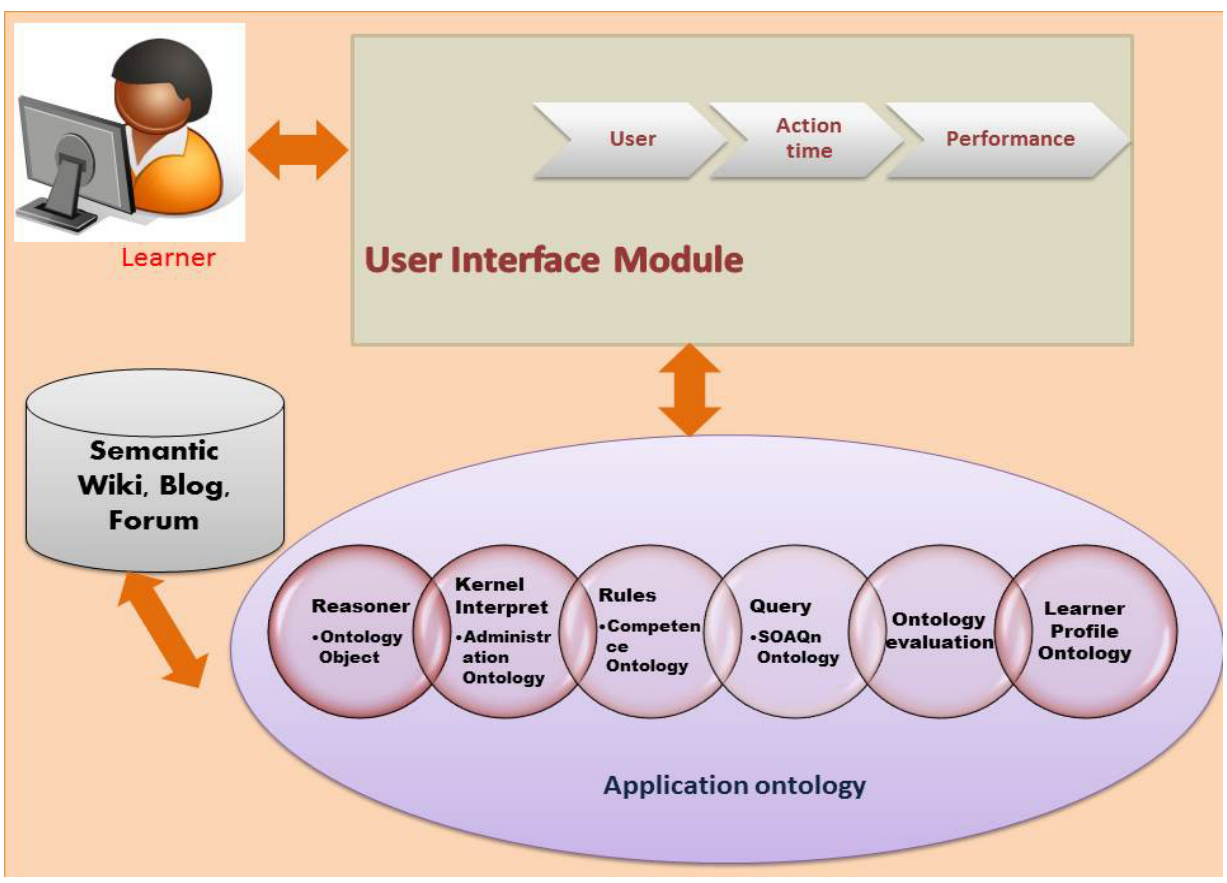

Fig. 2: Structure of learning and assessment system

One of the most important tasks of the pit involves connecting the ontologies between them in order to associate the set of notes in the request of searching educational complements on networks. The connections between the various ontologies can be represented under the form of a graph. This graph results of the data stemming union from the system six ontologies for a given learner.

\section{Stakes in the customization}

The main goal of customization is questioning in a training career. The daily regular disciplines in the variety of platforms of social Web do not mean necessarily that they will be reproduced in the same way during the academic university learning. To avoid that, we recommend registering the use of the semantic and active system of learning in a collective frame as well as defining the common shared objectives within an interest community. This system was intended to be flexible and evolutionary.

\section{A diversity of platforms and uses}

The first stake of customization is an issue of variety of platforms and uses forming what were characterized as social Web. Our primary questioning at this level of analysis deals with the different methods of the possible articulation between the practices of creation of contents, sharing, remixing, marking, vote etc., that are very broadly spread among the young people in their everyday life and the different types of practices such as marking, evaluation, comments etc. within the framework of institutional practices of learning at school. Probably, the practices describing social Web form a group of well anchored tendencies of the students' everyday life and also show an appropriate context especially in the use of the learning system based absolutely on the type of students' participation. In logic of sector of uses [1], these practices can be explained as a favorable base to found an active and also a semantic system of learning. The students have then developed habits of 
location as well as division, tagging and also comments of contents, independently, in their daily practices of the social media (YouTube, Facebook, Wikis ) but also forums, blogs, instant messaging etc. Still, these practices are of diverse meanings of use and depend on a set of platforms and devices which would be inacceptable to unify them under the social media vocabulary. Certainly, we think that the daily applications of the students on the social media are obviously of individual nature. They raise from a matter of variety of meanings use going from friendship practices to a purpose to be together, as to base on an interest, of being located. Nothing asserts that the same practices, moved in the learning context will have the same meanings use at school. In other words, the same practices of tagging and marking can be accomplished in valuation optics of one in a context and sharing of contents in another. Also, the different platforms accumulated under the word of social media do not represent at all the same opportunities in terms of institutional learning. With reference to the mapping of the social media proposed by Stenger and Costing [2] and of the interpretation of the opportunities open to the marks [3], we can assume that certain zones of the mapping and consequently certain platforms are not suitable to be used in any way in a learning context during university study. In this paper, the full development of this idea, in more details, is not possible for us. Nevertheless, clearly, we think that sociability platforms based on logics of friendship and presentation of one, like Facebook, are the field of a playful as well as generational culture, in which it sounds deceptive for us to establish institutional learning practices. In contrast, logics of content sharing platforms and interest follow-up, such as YouTube, Wikipedia, Twitter, Flickr, etc., develop many devices much more suitable to these kind practices.

\section{The personalization of the learning in a collective framework}

The preceding part figures out uses and platforms which can guide the learner when searching educational complementary means in the web in a case of need or simply if being curious. Accessibilities provided by the new technologies facilitate this practice and encourage the learners to developing it more. The learner is estimated to work when he wants, with whom he wants, and on what he chooses. This new method of learning inspired from a new learning theory allows us to conceive that a learner uses the system to fill its gaps or to move forward faster. This usage appears to be real as well as reasonable if the student has an adequate degree of autonomy and ambition. Then, we can mention self-directed learning, for which the system is a convenient tool. However, many searches on the remote teacher [4] come back to the required plain needs so that a learner gets his learning and organizes his work as well as shows up to be responsible and in the same time active. We know that the initiation of the new technologies does not assume mainly that the learners developed or develop metacognitive capacities needed to make a persuasive use. That is why we suggest registering the system use in a group of learners to support its usage on the metacognitive plan. The group has to meet regularly in the same physical place which is the class. The challenge is then to lean on a group dynamics, to build in the class, to extend this physical space over the walls to networks involving additional teaching aids. To accomplish this objective, we lean on a socio constructivist vision of the learning [5]. The socio constructivist approach reinforces the teamwork. Every member becomes coresponsible of the success of the team. In fact, he considers that to exchange in learning is a Factor that has an important role in increasing the common knowledge. The exchanges are developed to co-build knowledge. The teacher is no longer the usual influencer; he becomes the adviser and 
more than that the facilitator. In other words, he guides.

\section{Personalized career}

Contrary to the individual applications connected to social Web, we highlight the convenient features of the trained group by the learners and one or several teachers [6]. These characteristics seem to be crucial to support a mutual approach of using an active and semantic learning system. One of these characteristics lies in the presence of a shared and common purpose. Actually, the group is connected to a shared purpose to achieve knowledge acquisition and proficiency Even if the degrees of asset and motivation can differ individually; we can assure prior that this shared purpose is logical for the training characters. For that, the group can provide a community of interest for us. It is then settled around a weft which constitutes the common objectives to attain. This weft, realized by a pedagogical career (or learning career), recommends a timetable for acquired notions as well as the associated educational activities. Every activity contains teaching aids made by the teacher and/or from the Web.

Another characteristic of the group is established with reference to time. The group pursues the procedures of the educational course more or less with the same issue, with specific terms such as giving back a test. Every stage describes a phase for each learner and every towards the common purpose [8]. Worried to suggest a substantial personalization within a group and a remainder related to the learners' educational needs and the objectives, the educational program describes the axis that the personalized courses are going to articulate all-around of it. We start then a learning personalization related to the shared dynamics of perception and exchanges associated with the educational objects, dynamically linked to the collective concerns in the given times. Indeed, the teacher plays a much more organizational role to encourage the students using outside educational means. He coordinates, arouses as well as motivates them to use the educational complementary resources.

These collective practices facilitate extending educational valuable notes for the society. So, the learners can take into account the supports they have used outside the classroom. For a learner (or for a subgroup of learners) It happens to recommend for the group an educational material (ex: wiki) or an educational object used. This sharing will come to supply the system with the appreciations attribution (notes or Meta given onto the digital resources) assumed in a group. Still and all, ontology of the appreciations is organized in the system. This pooling of the appreciations allows therefore building step by step a valuable educational supports reference table for the entire group. At this moment, the group follows altogether the optics of semantic Web that recommends reusing the contextualized contents published on the Web. It is due to the fact that these appreciations will be related to the context determined by the needs of the community interest which will be reusable better and better afterward. In fact, they become important carriers for learners. Moreover, the note in a group of documents, looks to be formative to us due to being generator of new knowledge. Another notable interest related to the creation of appreciations, is to build up a critical mind, with connection to web publications, for the learners. The teacher plays here a role of master and presenter. $\mathrm{He}$ brings his proficiency and competence to manage the debates as well as end on the validity of notes.

\section{A flexible and evolutionary system}

The active and semantic system of learning leans on the data set semantic that characterizes the convenient learner's profile for every research, at this moment.[7] The filtering Semantics of the educational materials is consequently made by relating the profile of the evolutionary learner to Meta data given of the educational resources. We can affirm that this system is 
evolutionary and flexible as far as it can clarify the learners' options, starting from their prints in the digital networks, by acting, for example, through the educational resources cross-checking, appreciated especially by any learner. The system is regarded to be an asset by its basic capacity to be automatically adapted to the progress of the publications on Web. Furthermore, the flexibility of the system lives evolutionary in its handling by the users. A stumbling block pointed in the suggestion of computing tools which instrument the customization of leanings, lies in the effort supplied by the teacher to learn to use the numerous tools interface.

\section{Conclusion}

A method to propose the training routes personalized careers includes using an active and semantic system of learning. This system belongs to the current context marked by the daily practices development of contents division related to the social Web and the evolutions of semantic Web. It is founded to be both flexible and evolutionary. In order to achieve the personalized predicted objectives, we recommend using the system in a collective frame marked by a socio constructivist approach with the learning and distinguished by common objectives shared within a community of interest. The purpose of this system is to pick out better digital educational resources (rather pedagogical objects) to enhance the learning of the learner. The filtering of these educational complements given to measure and in due course takes into consideration the learners 'peculiarities and the objectives to achieve. It will be smarter and smarter, if a large number of educational resources are published on networks. That is why it is crucial for us to promote writing and publishing educational means, on the digital networks. This movement goes hand in hand with the development of standard associated notes schemes. The critical characteristic of this system lies in the design of the expanding significant ontologies for the domains supported by the system (six ontologies). When the system will soon introduce a phase of test, a reflection will be led on the efficiency of its ontologies.

\section{References}

[1] Mallein Philippe et Yves Toussaint. 1994. L'intégration sociale des technologies d'information et de communication. Une sociologie des usages. Technologies de l'information et société. no. 4. p. 315-335.

[2] Stenger, T., \& Coutant, A. (2013). Médias sociaux: clarification et cartographie Pour une approche sociotechnique. Décisions marketing, 107-117.

[3] Coutant, Alexandre, and Jean-Claude DOMENGET. "Le web participatif a-t-il besoin des marketeurs?." Actes du colloque Web social, communautés virtuelles et consommation, 79e congrès international ACFAS, Chaire de relations publiques et communication marketing, UQAM, Université de Sherbrooke. Vol. 11. 2011.

[4] Bourda, Yolaine. "Des objets pédagogiques aux dossiers pédagogiques (via l'indexation)." Document numérique 6.1 (2002): 115-128.

[5] Boroditsky, Lera. "Does language shape thought?: Mandarin and English speakers' conceptions of time." Cognitive psychology 43.1 (2001): 1-22.

[6] D. S. Boumiza and W. Ben Khalifa, "Design of an evaluation system in elearning Arabic language," International Conference on Education and e-Learning Innovations, Sousse, 2012, pp. 1-4.doi: 10.1109/ICEELI.2012.6360670

[7] Wiem Ben Khalifa; Boumiza, Dalila Souilem; Neji, Mahmoud. "Modeling of an evaluation system based on 
ontologies in a distance learning of the Arabic language" International Journal of Computer Science and Information Security; Pittsburgh14.11 (Nov 2016)

[8] Ovando, Martha N. "Teachers' perceptions of a learner-centered teacher evaluation system." Journal of
Personnel Evaluation in Education 15.3 (2001): 213-231.

[9] Salem, Safa Ben, et al. "Short and Open Answer Question Assessment System based on Concept Maps." Journal of Information Technology Research (JITR) 9.3 (2016): 49-67. 